\title{
PhotoPhage: A Virus-Based Photothermal Therapeutic Agent
}

\author{
Arezoo Shahrivarkevishahi, Michael A. Luzuriaga, Fabian C. Herbert, Alisia C. Tumac, Olivia R. \\ Brohlin, Yalini H. Wijesundara, Abhinay V. Adlooru, Candace Benjamin, Hamilton Lee, Perouza Par- \\ samian, and Jeremiah J. Gassensmith*
}

Department of Chemistry and Biochemistry, The University of Texas at Dallas, 800 West Campbell Rd., Richardson, TX 75080, USA. E-mail: gassensmith@utdallas.edu KEYWORDS: virus-like particles, immunophotothermal agent, combinational cancer therapy, NIR photothermal agent.

\begin{abstract}
Virus-like particles (VLPs) are multifunctional nanocarriers with the pathogenic-like architecture of viruses. They can serve as a safe platform for specific functionalization and immunization, which provides benefits in a wide range of biomedical applications. In this work, a new generation immunophotothermal agent is developed that adjuvants the photothermal ablation using a chemically modified VLP called bacteriophage Q $\beta$. The design is based on the conjugation of nearinfrared absorbing croconium dyes to lysine residues located on the surface of $Q \beta$, which turns it to a powerful NIR-absorber called PhotoPhage. This system can generate more heat upon $808 \mathrm{~nm}$ NIR laser radiation than free dye with a photothermal efficiency comparable to gold nanostructures yet is biodegradable and acts as an immunoadjuvant combined with the heat it produces. The synergistic combination of thermal ablation with the mild immunogenicity of the VLP leads to effective suppression of primary tumors, reduced lung metastasis, and increased survival time.
\end{abstract}

\section{INTRODUCTION}

Photothermal therapy (PTT) has emerged as a localized, noninvasive, and highly specific cancer treatment strategy that takes advantage of the heat sensitivity of cells to induce cellular death in tumors. ${ }^{1-3}$ The cellular death and injury promote the formation of damage associated molecular patterns (DAMPs) that aid in generating a systemic immune response against tumor sites. ${ }^{4-6}$ Typically, to achieve an efficient thermal ablation in the tumor microenvironment (TME), heating over $50{ }^{\circ} \mathrm{C}$ is required.7 The induced inflammation kills cancer cells by impairing protein and DNA function in addition to turning "cold" immune-dysfunctional TMEs into "hot" immunological environments by stimulating the production and release of DAMPs that prime the formation of activated dendritic cells and promote the production of cancer killing CD8+ T-cells. ${ }^{8-9} \mathrm{An}$ important factor to induce an effective immunological response in PTT treatment is using efficient photoabsorbers, particularly those that absorb light in the near-infrared (NIR) region (700$1100 \mathrm{~nm}$ ), where biological molecules like hemoglobin and melanin are the most transparent. ${ }^{10}$ Organic-based photoabsorbing molecules and inorganic nanomaterials are the most commonly employed preclinical photothermal agents (PTAs) that absorb light in NIR region and facilitate efficient heat production. ${ }^{11-12}$ The NIR region allows for deeper light penetration through skin and several photothermally active NIR organic molecules such as heptametine ${ }^{13-14}$ and phthalocyanine ${ }^{15-16}$ represent an ongoing area of research. Problematically, many of these dyes, including the clinically approved indocyanine green (ICG), degrade rapidly from a self-inflicted generation of reactive oxygen species (ROS), which necessitates repeated dosing for effective PTT treatment.17-180ne approach to overcome these issues is with the use of inorganic PTAs like nanostructures, ${ }^{19}$ carbon nanomaterials ${ }^{20}$ and iron oxide nanoparticles, ${ }^{21}$ which have shown strong absorption cross-sections and high photothermal stability; however, metal-nanoparticles, particularly those made from gold, are generally not biodegradable and remain inside the body for long periods. ${ }^{22}$ Finding a balance between high photothermal stability and pharmacokinetics is a key challenge in selecting suitable photothermal materials to simultaneously improve the therapeutic effect of PTT and fulfill its clinical efficiency. Recently, croconium dyes have shown promise as they possess high NIR extinction coefficients, low fluorescence quantum yields, and high photostability making them promising candidates for photothermal therapy. ${ }^{23}$ Indeed, recent work has shown they have photothermal efficiencies comparable or even surpassing those of gold nanostructures and ICG. ${ }^{24}$ However, their in vivo performance is restricted by poor aqueous solubility, self-aggregation, short circulation half time, quick diffusion from tumor tissue, and rapid clearance from the body. ${ }^{25-26}$ We wondered if it were possible to combine the superior photophysical properties of the croconium system with a biodegradable nanoparticle platform to produce a nextgeneration PTT agent that induces effective thermal ablation while also adjuvanting PTT's immune-activating properties

Virus-like particles (VLPs), noninfectious self-assembled protein-based nanoparticles derived from the selfassembled coat proteins of viral capsids, are promising candidates for next-generation bioorganic-based photothermal agents. VLPs are biocompatible, biodegradable, thermally stable, monodisperse, and show polyvalent chemical 
modifiability, which all provide unique opportunities to design bespoke compositions with programmed function. ${ }^{27-34}$ Their highly organized and symmetric nature and nanometer size $(20-200 \mathrm{~nm})$ allow them to be taken up by toll-like receptors (TLRs) on antigen-presenting cells (APCs) as pathogen-associated molecular patterns (PAMPs) and drained to local lymph nodes to interact with immune cells. These properties have made VLPs attractive in a broad range of systems such as drug delivery, vaccination, gene therapy, and imaging. ${ }^{35-46}$ VLPs expressed in bacteria, including bacteriophage $Q \beta$, incorporate nucleic acids (RNA) during the assembly process in host cells ( $E$. coli ) that can alter the adaptive immune response through the engagement of the packed RNA with different pattern recognition receptors (PPRs). Nevertheless, most VLPs are inefficient in inducing a robust cytotoxic $\mathrm{T}$ lymphocyte and $\mathrm{T}$ helper cell response by themselves. Thus, we wondered if the mild immunogenicity of $Q \beta$ would synergistically work with NIR light-activated hyperthermia to promote a more robust anti-cancer immune response that combines all the positive features of gold nanostructures (efficient thermal conversion) with free croc dyes (biodegradability).

In this work, we take advantage of the self-adjuvating and site-specific functionalizability of bacteriophage $Q \beta$ to engineer a photothermal and the mildly immunogenic phage (or VLP) we call PhotoPhage. The formulation is an effective photo-immunotherapy system in a triple-negative breast cancer tumor model in BALB/c mice with lung metastasis. Specifically, we show that VLP Q $\beta$ (Figure 1A), a 30 $\mathrm{nm}$ icosahedral nanoparticle that can be expressed in high yields, possesses exceptional thermostability, and has multiple functional handles for bioconjugation ${ }^{47-51}$ serves as a powerful photothermal agent following functionalization with hundreds of croconium dyes. Not only can PhotoPhage sustain significant bulk photothermal heating in vitro and in vivo without denaturing, but the nanoparticle formulation also shows a significant enhancement in photothermal performance over free dye and considerable improvements in solubility. Moreover, PhotoPhage partitions into cells better than free croconium dye and achieves significantly greater heating in vivo than equimolar concentrations of free dye. Finally, in proof-of-principle immunological studies, we find that this contribution not only causes higher in vitro and in vivo thermal cytotoxicity but also improves T-cell and dendritic cell activation over the well-known mildly immunomodulatory features of VLP $Q \beta .{ }^{52-55}$

\section{RESULT AND DISCUSSION}

\section{PhotoPhage Synthesis and Characterization}

As shown in Figure 1A, our approach for the covalent modification of bacteriophage $Q \beta$ begins with synthesizing a symmetric croconium dye. $Q \beta$ VLP is composed of 180 identical capsid proteins, each with four reactive primary amine groups (three lysines and $\mathrm{N}$-terminus) exposed to the outer surface, presenting a total of 720 potential sites for Croc dye labeling. Bioconjugation was employed using N-hydroxysuccinimidyl (NHS) ester activated Croc (Croc-NHS) as a site-specific and amine-reactive reagent. The resulting symmetric dye can potentially crosslink two VLPs, which produces aggregates that precipitate out of solution. To avoid this, the ratio and concentration of dye to $Q \beta$, incubation time and purification procedures needed optimization. We found that 1:4 mole ratio of $Q \beta$ to dye and $12 \mathrm{~h}$ incubation time produced the best colloidal stability, particle size, and dye loading for our final product, PhotoPhage. Denaturing polyacrylamide gel electrophoresis (Figure 2B left) shows an upward shift of the subunit bands of PhotoPhage, indicating an increase in the molecular weight compared to $Q \beta$. Native agarose electrophoresis of the conjugate, which is visually seen as the blue band in the bright field image in Figure 1B center, shows greater migration toward the positive electrode compared to unfunctionalized $\mathrm{Q} \beta$ (Figure 1B, right), in line with the expected greater negative charge from the free carboxylates. Product morphology was confirmed by transmission electron microscopy (TEM) and dynamic light scattering (DLS) analysis (Figure 1C) at $25^{\circ} \mathrm{C}$, which shows a nearly unchanged hydrodynamic radius from unfunctionalized $Q \beta(32.95 \pm 0.12 \mathrm{~nm})$ following attachment of the Croc dye $(33.10 \pm 0.15 \mathrm{~nm})$. The total number of dyes per capsid was determined to be approximately 1.2 by UV-Vis analyses, giving an average of 212 dyes per VLP.

A)
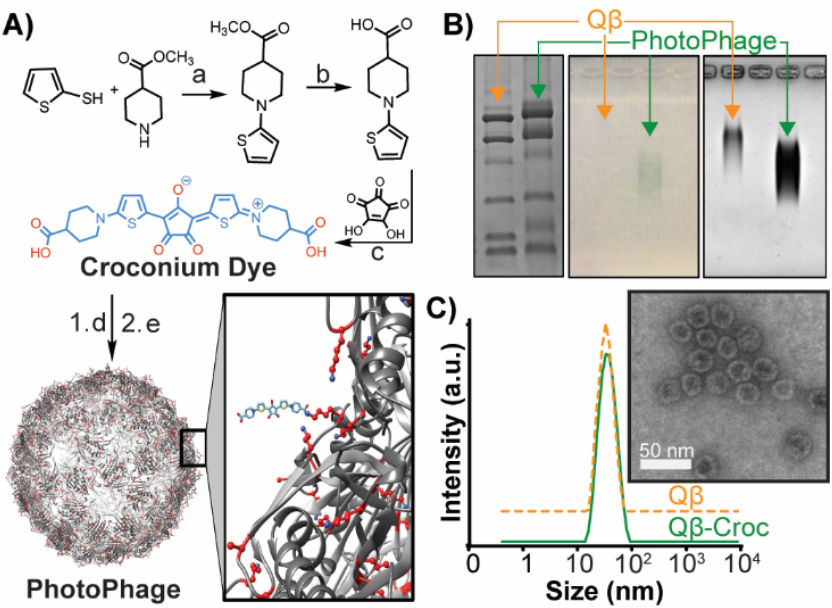

Figure 1. A) The overall synthetic bioconjugation strategy involves synthesizing the croconium dye by arefluxing commercially available starting materials methyl isonipecotate and thiophene-2-thiol. bThe resulting ester was deprotected under alkaline conditions and cthe final dye, Croc (thiophene-croconaine dye), was produced in the condensation reaction between croconic acid. The free acids were dactivated as n-hydroxylsuccinimide (NHS) esters and eadded under dilute conditions to a solution of $Q \beta$ to prevent crosslinking. The functionalized $Q \beta$ was incubated briefly in water to hydrolyze the remaining NHS esters back to the free acid. B) Electrophoresis mobility analysis of $Q \beta$ before and after conjugation on SDS-PAGE (left) and agarose (center and right) gels show successful bioconjugation of dye to $Q \beta$. Non-reducing SDS-PAGE shows an increase in molecular weight of $Q \beta$ after bioconjugation. The unstained agarose (center) shows a green band in bright light in the same spot in which a Coomassie-stained band (right) appears. The conjugate travels further toward the (+) electrode, which is anticipated from the replacement of lysines with carboxyl functions. C) DLS and TEM (insert) of Q $\beta$ and PhotoPhage demonstrate that the conjugation of croconium dye does not affect the size or polydispersity of the VLP.

Dyes used in PTT are most efficient when they are intensely colored and cannot dissipate energy through radiative relaxation pathways, e.g. fluorescence, or electron transfer, or 
intersystem crossing. Croc is well suited for this as it has strong NIR absorption $\left(\lambda_{\max }=783 \mathrm{~nm}, \varepsilon_{\max }=2.0 \times 10^{5} \mathrm{~mol}^{-1}\right.$ $\mathrm{cm}^{-1}$ in water), 56 negligible fluorescence, and low oxygen photosensitization - which also improves its photostability - a known issue with ICG and the extensively investigated heptamethine dyes. We were pleased to find that PhotoPhage exhibits a strong NIR absorption maximum $\left(\lambda_{\max }\right.$ $783 \mathrm{~nm}$ ) identical to that of free croconium dye, yet the absorption spectrum is significantly broadened (Figure 1A). This broadening is pronounced in the NIR region, which promotes more efficient conversion of clinically used lasers (emissions centered at $808 \mathrm{~nm}$ ).
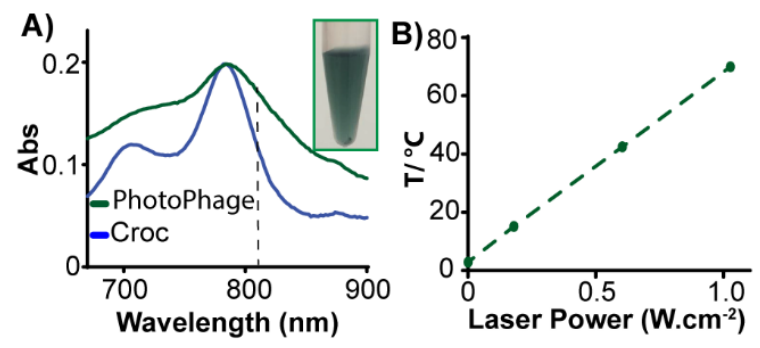

C)
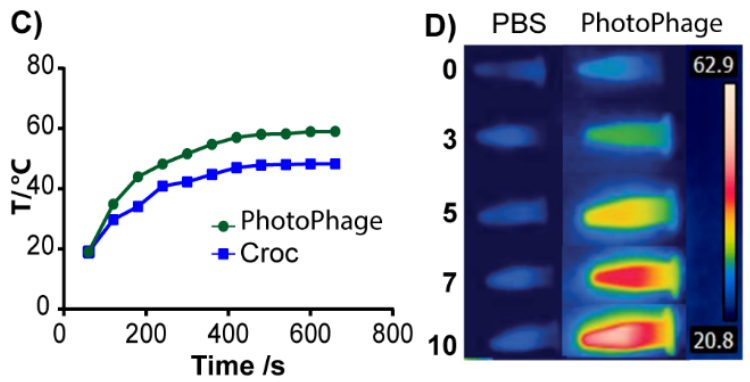

Figure 2. UV-Vis Spectrographic analyses of equal Molar concentration chromophores of Croc and PhotoPhage show A) a broadening of the NIR absorption of PhotoPhage (green line) compared to croconium dye (blue line). A photograph of PhotoPhage is shown in the insert. B) A linear relationship exists between PhotoPhage $\left(30 \mu \mathrm{g} . \mathrm{mL}^{-1}\right)$ solution temperature increases and laser power after 3 mins of irradiation (laser power was set $0.0015,0.18,0.604,1.02 \mathrm{~W} \cdot \mathrm{cm}^{-2}$ ). C) Photothermal heating profile of PhotoPhage and Croc at the same concentration $\left(30 \mu \mathrm{g} \mathrm{mL}^{-1}\right)$ after 11 min laser irradiation (808 $\left.\mathrm{nm}, 0.18 \mathrm{~W} \cdot \mathrm{cm}^{-2}\right)$ shows a significant difference in temperature increase $\left(40.1^{\circ} \mathrm{C}\right.$ for PhotoPhage and $29.1^{\circ} \mathrm{C}$ for Croc). D) Temperature variations of PhotoPhage and PBS under laser irradiation are mapped and quantified by a thermal camera. No noticeable temperature increase was observed in PBS under the $808 \mathrm{~nm}$ laser irradiation $(0.18$ $\mathrm{W} \cdot \mathrm{cm}^{-2}$ ) at different time points.

This effect was made apparent when we compared the bulk solution photothermal response of PhotoPhage and free dye. Both solutions containing an identical concentration of chromophore $\left(30 \mu \mathrm{g} . \mathrm{mL}^{-1}\right)$ were fitted with a thermocouple and placed in front of a thermal camera. Temperature change in each solution was monitored over $11 \mathrm{~min}$ of laser irradiation at $808 \mathrm{~nm}$ and $0.18 \mathrm{~W} \cdot \mathrm{cm}^{-2}$. As seen in Figure 2C, the solutions showed a marked difference in heating rates and maximum temperature with PhotoPhage showing a $\Delta T$ of $40.1^{\circ} \mathrm{C}$ and a $T_{\max }$ of $59.1^{\circ} \mathrm{C}$ compared to free dye $(\Delta \mathrm{T}$ : $29.9^{\circ} \mathrm{C} T_{\max }=48.5^{\circ} \mathrm{C}$ ). Additional laser irradiation experiments have been done to investigate photothermal properties of PhotoPhage at different laser powers $(0.0015$, $0.18,0.604$ and $1.02 \mathrm{~W} \cdot \mathrm{cm}^{-2}$ ), times of radiation (1-10 $\left.\mathrm{min}\right)$, and various concentrations (0.1-1 $\mathrm{mg} \cdot \mathrm{mL}^{-1}$ ) of PhotoPhage. For instance, we found a linear increase in the bulk temperature of the solution that is linear with laser power (Figure 2B and Figure S10). Collectively, the PhotoPhage appears to have superior photothermal properties compared to free dye, which allows for lower laser power density and dye concentration, potentially reducing side effects on normal tissue. To show that the $808 \mathrm{~nm}$ laser does not change the temperature of the water itself, we irradiated a solution of buffer and PhotoPhage (Figure 2D and S10) and observed no temperature change in the PBS solution, whereas we could heat a solution of PhotoPhage from room temperature to $61^{\circ} \mathrm{C}$ with an $808 \mathrm{~nm}$ laser at $0.18 \mathrm{~W} \cdot \mathrm{cm}^{-2}$.
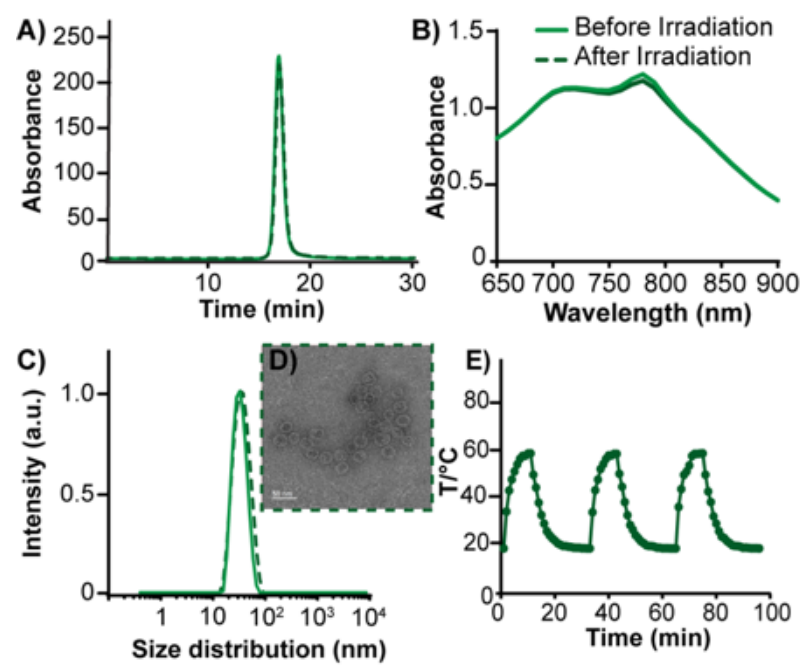

Figure 3. A) Photothermal stability of PhotoPhage after $10 \mathrm{~min}$ laser irradiation $\left(0.18 \mathrm{~W} \cdot \mathrm{cm}^{-2}\right)$ is shown by intact HPLC profile of PhotoPhage before and after radiation. B) No significant change in absorption spectra of PhotoPhage after laser-induced heating for 10 min. C) DLS and D) TEM data prove thermal stability of PhotoPhage with no morphology change after 10 min laser irradiation. E) Thermal cycling of PhotoPhage shows no change in heating profile after three cycles.

The photothermal stability of the PhotoPhage complex was proven by comparing size distribution, absorption, and size exclusion chromatography before and after $10 \mathrm{~min}$ of continuous laser irradiation $\left(0.18 \mathrm{~W} \cdot \mathrm{cm}^{-2}\right)$ as shown in Figure 3A-D. The results showed no photobleaching, aggregation, or structural change, indicating high photostability of the system. To demonstrate the remarkable stability of the PhotoPhage, we performed a thermal cycling experiment. A PhotoPhage solution ( $30 \mu \mathrm{g} \cdot \mathrm{mL}^{-1}$ of Croc concentration) was irradiated repeatedly $\left(808 \mathrm{~nm}, 0.18 \mathrm{~W} \cdot \mathrm{cm}^{-2}\right)$, and the temperature was monitored over the heating and cooling cycles, as shown in Figure 3E. The PhotoPhage showed impressive photothermal durability over at least three cycles with no apparent change in the maximum temperature. In line with strong absorbance in the NIR region and high photostability, we further determined the photothermal efficiency of the PhotoPhage and compared it with existing photothermal materials - free Croc dye and gold nanorod 
(AuNR). ${ }^{57}$ We found that the Photophage has higher photothermal conversion efficiency (77\%) compared to Croc alone (70\%) and AuNR (68\%), which is in line with the literature (Figure S11). From these results, we believe that the high photostability, durability, and remarkable photothermal conversion efficiency of PhotoPhage make it a good candidate for PTT. 58

\section{PhotoPhage In Vitro Cytotoxicity}

Cellular uptake of both PhotoPhage and free Croc was assessed on 4T1 (murine breast cancer) cells. Because Croc lacks fluorescence, we determined uptake by measuring the amount of remaining dye in the supernatant after a $4 \mathrm{~h}$ incubation period. In a typical experiment, PhotoPhage and Croc were added to media containing equal chromophore concentrations, and after $4 \mathrm{~h}$, the cells were removed, the media filtered, and the total absorption at the $\lambda_{\text {max }}$ was compared before and after. All concentrations were within the linear range of Beer's law, allowing direct calculation of before and after concentrations. As shown in Figure S12, cellular uptake of PhotoPhage is about twice that of croconium dye. Croc, being negatively charged, is very unlikely to partition into the cell, and so these results were not surprising. Next, for the in vitro phototoxicity in 4T1 cells, the photoablation efficiency of PhotoPhage and Croc was determined by incubating identical concentrations $\left(3.1 \mu \mathrm{g} . \mathrm{mL}^{-1}\right)$ in cell culture. After $4 \mathrm{~h}$ incubation at $37^{\circ} \mathrm{C}$, cells were washed with PBS and fresh phenol red-free media to remove any remaining dye. Before laser irradiation, the microwell plate was equilibrated to $37^{\circ} \mathrm{C}$, as it has been shown in previous studies that initial temperature (RT vs $37^{\circ} \mathrm{C}$ ) has a significant effect on the in vitro PTT efficiency. All four experimental groups were exposed to an $808 \mathrm{~nm}$ laser for $10 \min \left(0.18 \mathrm{~W} \cdot \mathrm{cm}^{-2}\right)$. The next day, cell viability in each well was determined by MTT assay. As shown in Figure S13, all formulations before laser radiation showed low toxicity, whereas the cell viability of PhotoPhage dropped dramatically to $17 \%$ while free Croc dropped to only $65 \%$ after laser radiation. We attribute this greater cell killing from the improved cellular uptake and therefore greater

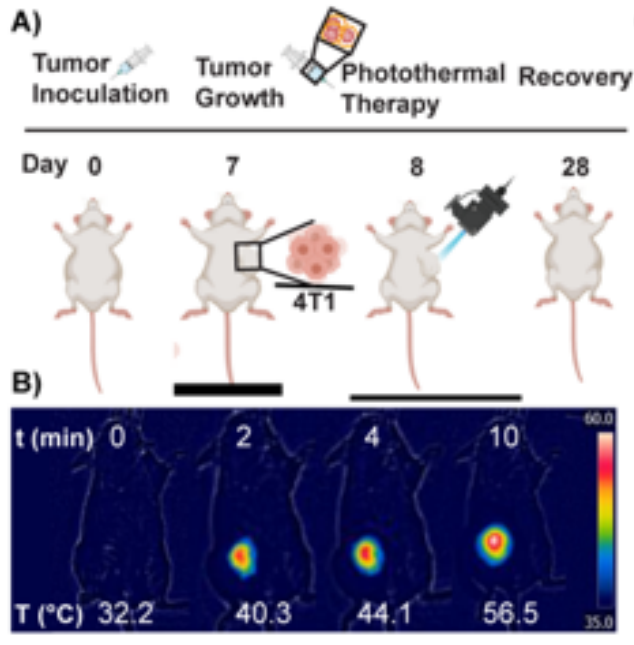

E)

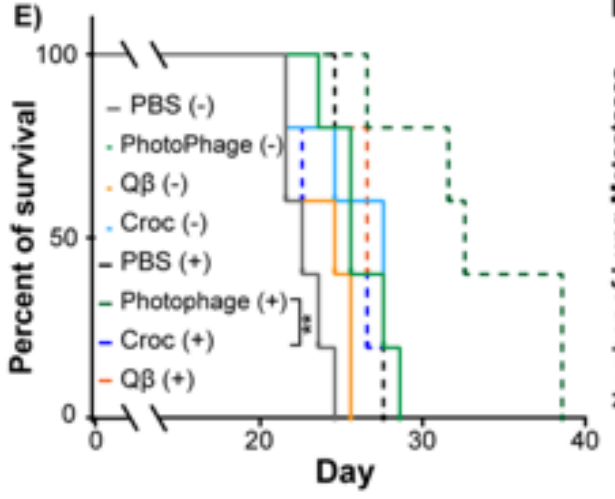

F)
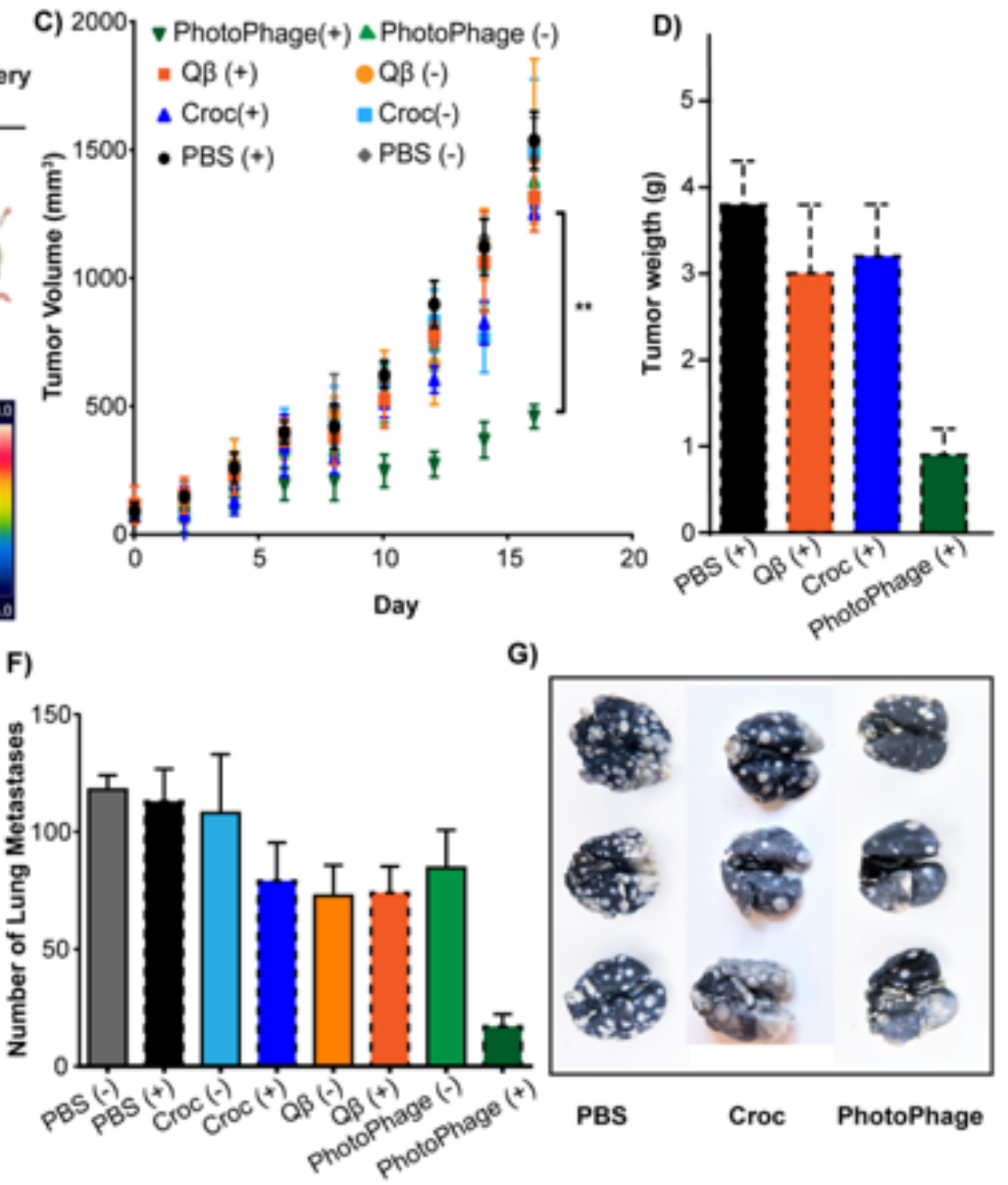

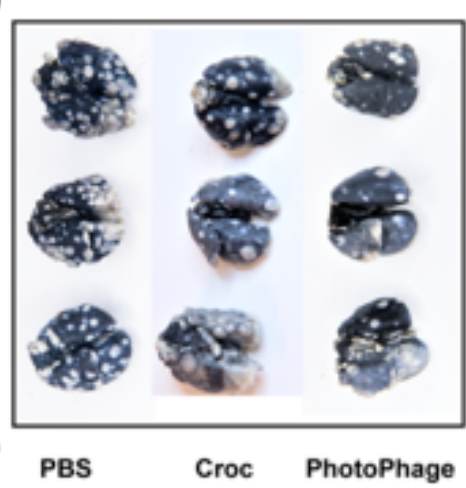

Figure 4. A) Experiment design of synergistic immunophotothermal therapy. B) Representative IR thermal images of tumor-bearing mice treated with PhotoPhage at different NIR radiation times $(808 \mathrm{~nm}, 0.18 \mathrm{~W} \cdot \mathrm{cm}-2,10 \mathrm{~min})$ after intratumoral (i.t.) injection. C) Tumor growth curves of 4T1 tumor-bearing mice treated with PBS, Q $\beta$, Croc and PhotoPhage with and without laser radiation showing the most effective therapeutic approach is attributed to PhotoPhag which exhibited the greatest restriction to tumor growth. D) Tumor weight as a representative of tumor suppression verified high anti-tumor performance of PhotoPhage compare to Croc, $Q \beta$, and PBS groups E) Survival study of 4T1tumor- bearing BALB/c mice $(n=5)$. F) Number of lung nodules after India ink staining. G) Representative images of India-ink-infused lungs of Croc, PhotoPhage and PBS mice that white spot clearly demonstrate number of metastatic nodules per each group. ${ }^{* *} \mathrm{p}<0.05$. 
intracellular heating. These results were qualitatively confirmed through visual analyses of cell viability via a dead cell assay (Figure S13). With these results in hand, we conducted in vivo anti-tumor studies to see if we would observe similarly improved response with PhotoPhage.

\section{Photothermal Anti-tumor Response In Vivo}

We assessed the anti-tumor effect of our system in the same murine mouse cancer model discussed above. 4T1 cells $\left(1 \times 10^{6}\right)$ were implanted into the abdominal mammary gland of 4-6-week-old female BALB/c mice. Tumor development was allowed to proceed until the average tumor size reached 5-6 $\mathrm{mm}$, after which mice were randomly divided into four groups with radiation and four groups without radiation for various treatment: PBS (negative control), $\mathrm{Q} \beta$, and identical concentrations (by chromophore) of Croc and PhotoPhage. Following randomization, mice from each group $(n=5)$ were injected intratumorally ${ }^{59}$ and $2 \mathrm{~h}$ later; laser treatment was performed $(808 \mathrm{~nm}, 0.18 \mathrm{~W} \cdot \mathrm{cm}-2,10$ $\mathrm{min}$ ) as schematically shown in Figure 4A. Intratumoral injections with photoactive therapeutics make sense, since the tumor must be accessible for irradiation. The effect of treatment was evaluated by monitoring the body weight of the mice and measuring tumor volume over $16 \mathrm{~d}$. Tumor volumes were measured using calipers every other day after treatment and calculated according to the equation: Vol $=($ tumor length $) \times($ tumor width $) \cdot 2 / 2$. The tumors treated with PhotoPhage plus laser irradiation developed a sizeable black scab on the tumor site and showed slower tumor growth compared to all other experimental groups. The bodyweight of each group was monitored over $16 \mathrm{~d}$, and we found no significant change, which suggests PhotoPhage, $\mathrm{Q} \beta$, and Croc did not induce toxicity (Figure S16). The irradiated Croc dye and $Q \beta$ by itself slightly delayed the growth of the primary tumor though nowhere near as much as the PhotoPhage formulation, which caused obvious tumor ablation after NIR laser exposure. The degree of tumor ablation and recission induced by different groups was further confirmed through tumor weight. As shown in Figure 4D, PhotoPhage again produced significant suppression on tumor growth compared to $\mathrm{Q} \beta$ and Croc alone. Survival of the different groups of treated tumor-bearing mice was studied over 38 days following the initial tumor inoculation. As shown in the Kaplan-Meier survival curve, illustrated in Figure 4E, only PhotoPhage prolonged survival time compared to other groups. Metastatic burden was evaluated at day 16 post-treatment by removing the lungs and staining them with India ink, which preferentially blackens healthy tissue making the metastasis stand out. Control groups (PBS) and unirradiated free Croc show statistically identical tumor burdens, as illustrated in Figure 4F and 4G. The unaltered $\mathrm{Q} \beta$ and irradiated free Croc groups all produced a modest and statistically significant decrease in metastatic burden. Summarily, the anti-tumor activity of PhotoPhage appears to be improved over free

\section{Immunological Studies}

While the scope of this work is primarily the synthesis and anti-tumor response of PhotoPhage, we wondered if the VLP was enhancing the immunological response initiated by the PTT. Detailed anti-tumor immunological studies will be addressed in subsequent work. Our initial focus in this part of the study was the assessment of dendritic and T-cell activation and an assessment of any downregulation of protective T-cell (Treg) response. In anti-tumor immunity, dendritic cells (DCs) are an important and effective class of APCs that plays a pivotal role in initiating and regulating innate and adaptive immunities. ${ }^{60}$ Generally, immature DCs ingest foreign materials through different surface receptors, including pattern recognition receptors that trigger their maturation. ${ }^{61-62}$ PRRs detect PAMPs (derived from microorganisms) and DAMPs (produced by the body's dying cells). Mature DCs can process antigens into peptides for presenting on major histocompatibility complex class I/II (MHC-I/II) molecules that coincide with increased expression of B7-1/CD80 and B7-2/CD86 costimulatory molecules. Following maturation and antigen exposure, DCs migrate into the draining lymph node-where contact is mediated between DCs and T-cells-and promote the differentiation and proliferation of naïve T-cells into cytotoxic $\mathrm{T}$ lymphocytes (CTLs), which are key effector cells for anticancer immunity. ${ }^{9}$ 63-65 Only mature DCs can elicit anti-tumor effector T-cell responses, which can be determined by assessing DC maturation in vitro following exposure to an antigen. It is well-known that VLPs mimic viruses in their size, structure, and antigenic epitopes. 66-67 Their 20-200 $\mathrm{nm}$ size is in the optimal diameter range that can directly drain to the lymph node. In addition, because of their regular polyhedron structure and highly repetitive surface feature, VLPs are sensed as PAMPs by PRRs on the surface of DCs. Furthermore, the encapsulated nucleic acids also can be recognized by PRRs and promote DC maturation for priming $\mathrm{CD}^{+} \mathrm{T}$ helper lymphocytes and $\mathrm{CD}^{+}$cytotoxic $\mathrm{T}$ lymphocytes. ${ }^{54}$ These cytotoxic T-cells can then fight systemic cancer at metastatic sites.

We first investigated whether $Q \beta$ stimulates the maturation of DCs by using cultured bone marrow derived DCs (BMDCs) separated from BALB/c mice and incubating them with different concentrations of $Q \beta$ for $24 \mathrm{~h}$. The expression of DCs maturation markers - proteins called CD80 and CD86 - were determined by staining them with anti-CD80 and anti-CD86 fluorescent antibodies and quantified using flow cytometry (FCM). We found that $\mathrm{Q} \beta$ upregulates the expression of CD86 \& CD80 and enhance the percentage of matured DCs (CD11 ${ }^{+} \mathrm{CD} 80^{+} \mathrm{CD}^{+} 6^{+}$) in BMDCs at all concentrations tested compared to PBS (Figure S14). Next, we focused on evaluating the adaptive immunity triggered by $\mathrm{Q} \beta$ at cellular levels after incubation with splenocytes harvested from a naïve mouse. Again, $Q \beta$ was mildly able to promote the effector $\mathrm{CD}^{+} \mathrm{T}$ helper lymphocytes $\left(\mathrm{CD}^{+}{ }^{+} \mathrm{CD}^{+}{ }^{+} \mathrm{CD} 44^{+} \mathrm{CD} 62 \mathrm{~L}^{-}\right)$and $\mathrm{CD}^{+}$cytotoxic $\mathrm{T}$ lymphocytes $\left(\mathrm{CD}^{+}{ }^{+} \mathrm{CD} 3{ }^{+} \mathrm{CD} 44{ }^{+} \mathrm{CD} 62 \mathrm{~L}^{-}\right)$, which show possible immunoadjuvant potential of $\mathrm{Q} \beta$ in the PhotoPhage system to stimulate anti-tumor immune responses (Figure S14).

PTT induces apoptosis and necrosis, efficiently destroys tumor cells, subsequently releasing debris containing tumor-associated antigens and chemokines. ${ }^{68-69}$ These antigens are subsequently taken up by DCs and trafficked to the lymph node, triggering anti-tumor immune responses. Furthermore, DAMPs released from necrotic cancer cells, such as heat shock proteins, calreticulin, and ATP, can also promote DC maturation and assist in activating effector $\mathrm{CD}^{+} \mathrm{T}$ cells that enter circulation to fight against primary and metastatic sites systemically (Scheme 1). ${ }^{6,70}$ Our data 


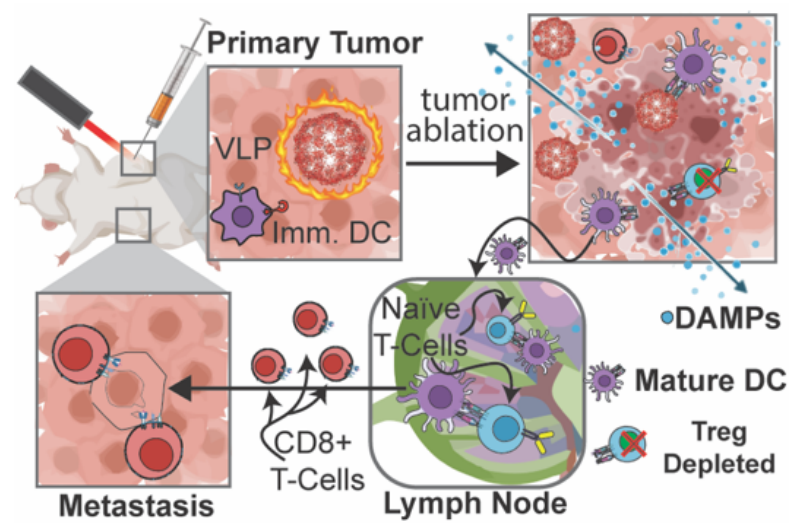

Scheme 1. Schematic illustration of PhotoPhage-initiated photothermally-triggered anti-tumor immune response. An initial photothermal excitation of the VLP causes an increase in temperature, which results in local tissue ablation. This causes local apoptosis/necrosis and the release of immune-stimulating DAMPs. The presence of intact VLP in the ablated tumor environment simulates a potential infection, which causes downregulation of immunosuppressive response by suppressing Treg cell formation. These responses can be measured in the draining lymph node. In this lymph node, cancer antigens collected by activated dendritic cells can present to naïve Tcells, which mature to cytogenic CD8+ cells. These cells can then attack metastatic lesions.

shows that $Q \beta$ can simultaneously act as an immunological agent to promote DC activation and enhance infiltration of CTLs. As shown in Figure 2C, PhotoPhage and Croc both show favorable photothermal effects in a wide temperature range $\left(40-60^{\circ} \mathrm{C}\right)$; thus, we set up our in vivo experiment to evaluate immunostimulatory activities of the combinational formulation compared to PTT alone. BALB/c mice were inoculated with 4T1 cells and grown until they had a primary tumor size of $100 \mathrm{~mm}^{3}$. The mice were separated into four groups $(n=5)$ and injected with PBS, $Q \beta$, Croc, or PhotoPhage (same dye concentration as free Croc). Two hours post-injection, they were irradiated with $808 \mathrm{~nm}$ laser for $10 \mathrm{~min}\left(0.18 \mathrm{~W} \cdot \mathrm{cm}^{-2}\right)$. We conducted our experiment initially by assessing identical concentrations (the same number of) NIR dyes are used with Photophage vsfree Croc group (as measured by UV-Vis), the temperature at the tumor surface ends up being higher for PhotoPhage $\left(54 \pm 2^{\circ} \mathrm{C}\right)$ compared to free Croc $\left(40 \pm 1^{\circ} \mathrm{C}\right)$ (Figure S17), which can be ascribed to a more rapid clearance of free Croc from the tumor and greater photothermal efficiency of Photophage at $808 \mathrm{~nm}$. Three days post-treatment, the mice were sacrificed, and the spleen and draining lymph node were collected to analyze the Tlymphocytes and mature DCs by flow cytometry after co-staining with various markers. It is worth noting that post-PTT the populations of immune cells within the tumors were all very low, likely from the photoablation, and getting statistically useful data from the tumors was difficult. Since our interest is in studying how PhotoPhage adjuvants the effects of ablative PTT, this was anticipated. We were able to get statistically meaningful data from the draining lymph and spleen, however, and these populations are generally useful in measuring local and systemic immune response in cancers. ${ }^{71,72}$ The percentage of matured DCs (CD11c+ CD80+ CD86+) in the draining lymph node from PhotoPhage was $24 \%$ greater than the Croc group, as shown by higher expression of costimulatory molecules CD80 and CD86 (Figure 5A), validating PhotoPhage's in vitro behavior, and showing it can enhance the activation of APCs better than each formulation alone. We also determined how PhotoPhage affects CD8+ T-lymphocyte cells in the draining lymph node and found a significant number of activated (CD44+ CD62L-) CD8+ T cells in the PhotoPhage group compared to other treated groups (Figure 5B). To exclude the effect of the more efficient photothermal and tumor residency of PhotoPhage, we analyzed DC maturation in the draining lymph node when tumor tissue temperature for both Photophage and croc group reached the same temperature after laser irradiation (this required different amounts of dye in each formulation). Multiple studies show that heating tumor cells at low temperature $\left(39.5-44^{\circ} \mathrm{C}\right)$ enhances blood flow in the tumor and improves the permeability of tumor vasculature and may promote better migration of DCs between tumor and lymphoid organs even if it is not as efficient as higher temperature range $\left(>45^{\circ} \mathrm{C}\right)$ in destroying the primary tumor. Therefore, we utilized $1.5 \mu \mathrm{g}$. $\mathrm{mL}^{-1}$ PhotoPhage and four times more the amount of Croc $\left(6.0 \mu \mathrm{g} . \mathrm{mL}^{-1}\right)$ used to produce a final tumor temperature of approximately $44{ }^{\circ} \mathrm{C}$ and maintained this temperature for $10 \mathrm{~min}$ by $808 \mathrm{~nm}$ laser irradiation. Intriguing, as shown in Figure $\mathbf{5 F}$ and $\mathbf{5 H}$, we observed the same general trends where PhotoPhage outperforms free dye significantly in stimulating DC and T-cells. Consequently, we do not think that temperature alone explains the anti-tumor results reported above.

We next checked T-cell responses from our approach. The population of activated effector CD8+ cytotoxic T-cell (CD8+CD44+CD62L-) and CD4+ T-cell (CD4+CD44+ CD62-) were quantified in spleens by FCM after various treatments. Compared to either Croc or $Q \beta$ alone, the combination treatment resulted in 2.10-fold increase in helper CD4+ T-cell and 2.12 fold increase in CTL CD8+ T-cells compared to Croc. $(\mathrm{p}<0.05)$. These results collectively demonstrate that PhotoPhage can act as a powerful photothermal agent along with potentiating PTT's immunological response. Next, spleen single-cell suspension of four different groups of mice were stained with antiCD11c, -CD4, -CD44, and -CD62L antibodies to measure how much effector memory T-cells were expressed after each treatment. As displayed in Figure 5G \& 5H, significant CD4+CD44+CD62L- cells appeared for mice treated with PhotoPhage. One limitation in most of radiotherapy systems is that, following tissue damage, the tumor microenvironment can develop which creates an immunological "cold" tumor that restricts the therapeutic performance. 8 , 73${ }^{74}$ Several studies have reported ${ }^{8,52}$ that the efficiency of PTT inversely correlates with Treg cells, an immunosuppressive subset of CD4+ T cells characterized by the expression of factor forkhead box protein P3 (FoxP3).

Necrotic cell death induced by PTT causes an inflammatory response that promotes the expression of Treg immunosuppressive molecules as a protective measure since an injury in a person such as a burn should not initiate a strong full-body immune response. We expected that $\mathrm{Q} \beta$ may amplify the immune response, and its presence as a foreign viral protein might "trick" the immune system into and 


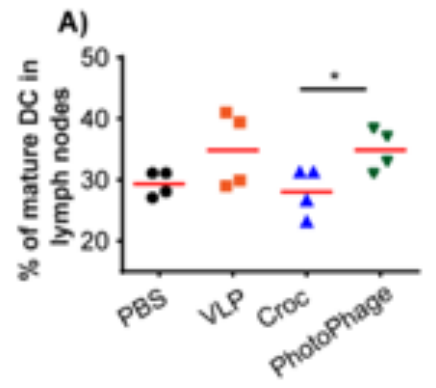

E)

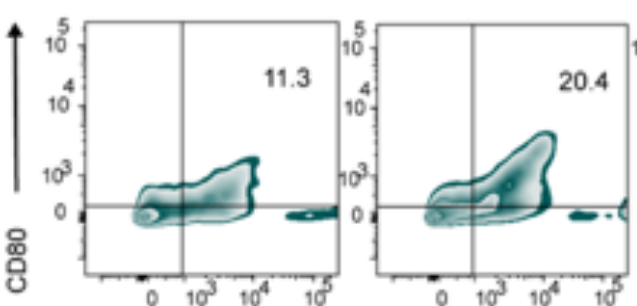

G) $\operatorname{CD} 86$

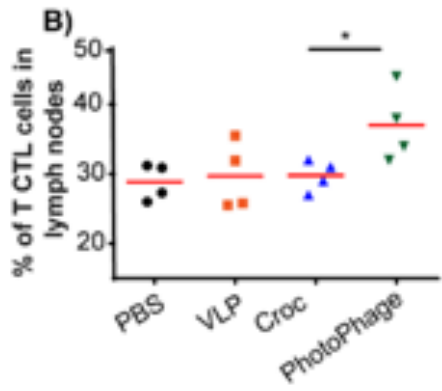

VLP
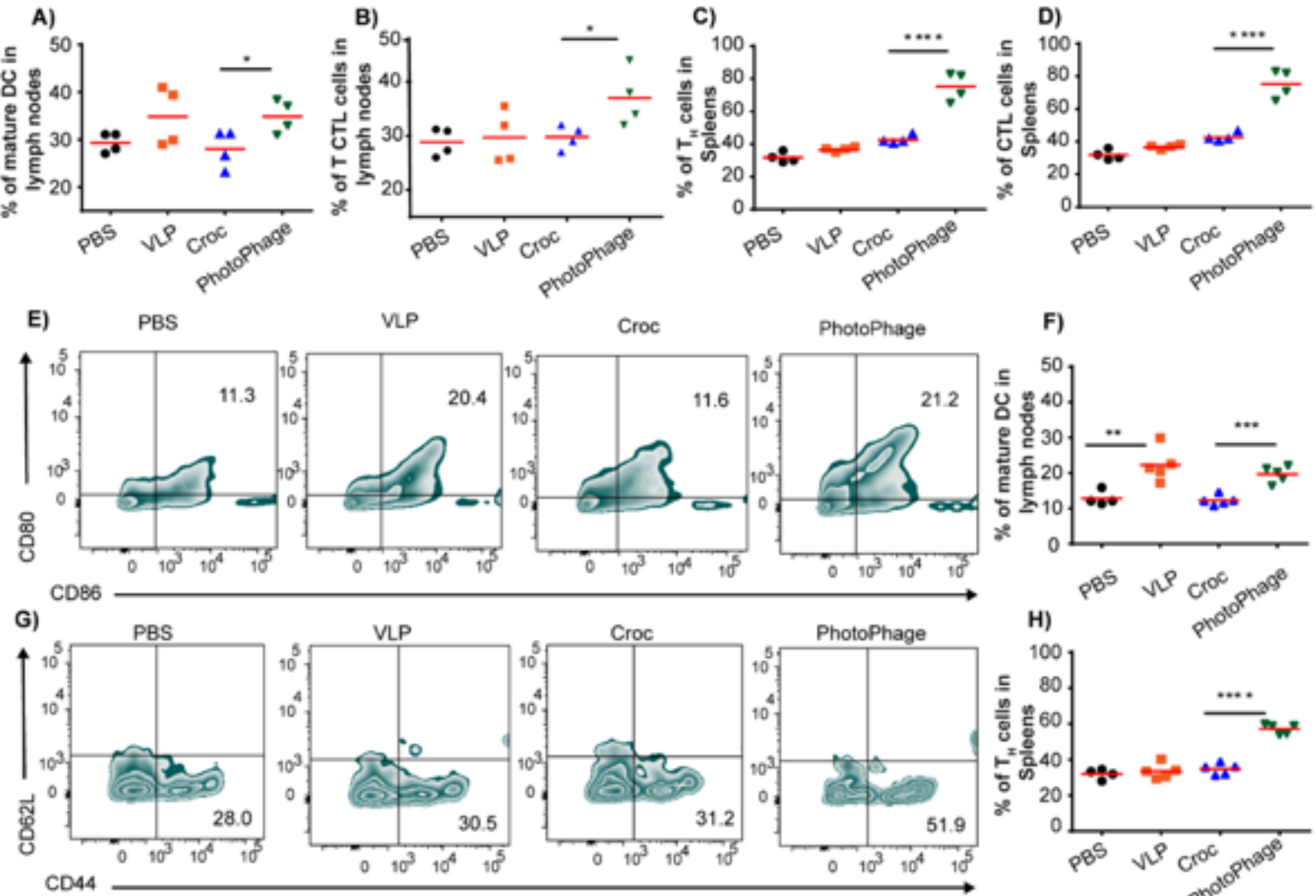

PhotoPhage

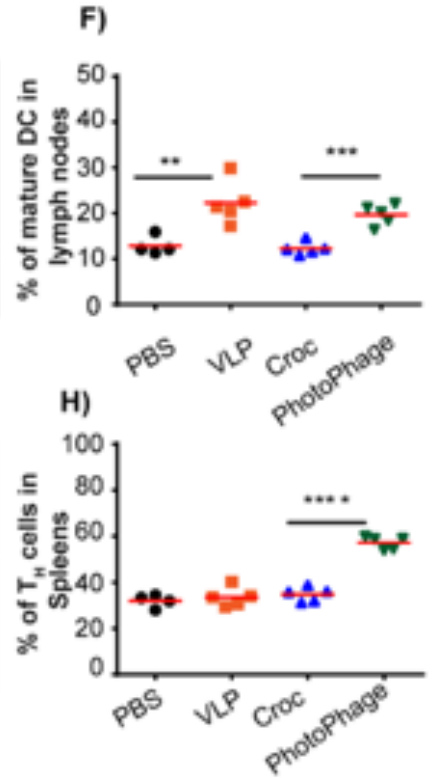

I)

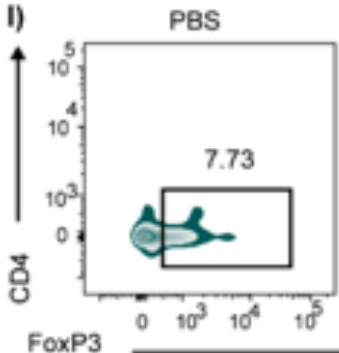

VLP
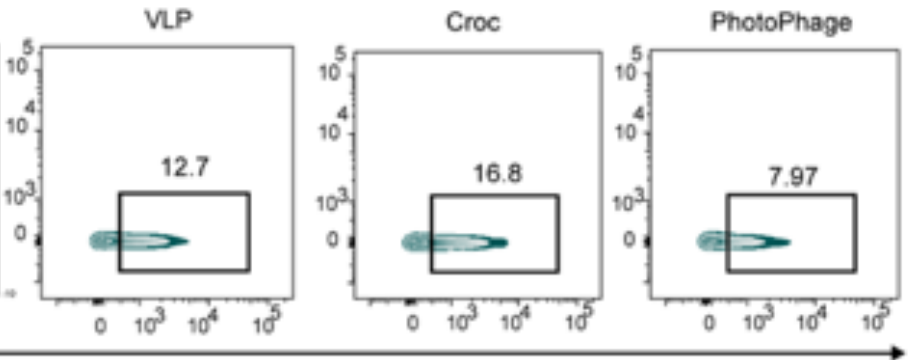

Figure 5. In vivo immune responses after the photothermal stimulation. A) DC maturation induced by various groups on mice bearing 4T1 tumors (gated on CD11 $\mathrm{c}^{+}$DC cells, Figure S15) after PTT treatment $\left(T_{\max }=54.2^{\circ} \mathrm{C}\right)$. Cells in the tumor-draining lymph node were assessed by flow cytometry after staining for CD80 and CD86 expressions. B) Quantification of CTLs (CD8+) in isolated lymph nodes. C-D) Percentage of helper T-cells (CD4+) and CTLs in spleens. Single-cell suspensions were processed from the spleen and analyzed by flow cytometry after anti-CD3, -CD4, -CD8, -CD44, and -CD62L staining $\left(T_{\max }=54.2^{\circ} \mathrm{C}\right)$. E-F) Representative flow cytometry plots showing expression of CD86 and CD80 on DC of draining lymph node at different groups (gated on CD11 $\mathrm{c}^{+}$, Figure S15) after PTT treatment $\left.\left(T_{\max }=44.0^{\circ} \mathrm{C}\right) . \mathrm{G}-\mathrm{H}\right)$ Representative flow cytometry plots of effector CD4+ in spleen cells of different treatment groups analyzed by flow cytometry (stained with anti- CD3, $-\mathrm{CD} 4,-\mathrm{CD} 44$, and $-\mathrm{CD} 62 \mathrm{~L})\left(T_{\max }=44.0^{\circ} \mathrm{C}\right)$. I-J) Representative flow cytometry plots showing percentages (gated on CD4+ cells, Figure S15) of CD4+FoxP3+ T cells in the spleen after various treatments.

turn off this immunosuppressive response. Therefore, we assessed the presence of CD4+FoxP3+ after different treatments by flow cytometry to investigate the ratio of the effector CD4+ T-cells vs. Treg in the spleen-an organ that serves as a systemic repository for the immune system. As expected - and shown in Figure 5I \& 5J - PTT alone produces a high suppressive environment while PhotoPhagea combination of PTT and the immunoadjuvanting agent $\mathrm{Q} \beta$-decreased the percentage of Tregs (lower CD4+FoxP3+).This is significant because cancer therapeutic efficacy associated with tumor suppression and higher survival time correlates with lower Tregs and higher effector T-cells.

\section{CONCLUSION}

In this work, we took advantage of VLP Q $\beta$ 's biocompatibility, functionalizability, and modest immunogenicity to produce a new synthetic-biomaterial hybrid PTT "PhotoPhage." This formulation significantly improved the 
photophysical properties, including photothermal conversion efficiency and water solubility, as shown by an enhancement of cellular death upon $808 \mathrm{~nm}$ laser exposure than free dye. In addition, this synergistic combination showed excellent NIR light-induced tumor ablation by suppressing $70 \%$ of the primary breast cancer tumor in BALB/c mice bearing a highly metastatic $4 \mathrm{~T} 1$ tumor compared to $18 \%$ of Croc alone. PhotoPhage also prolonged survival time and reduced lung metastasis by $85 \%$ compared to control. Our initial immunological screening strongly suggests that the VLP may adjuvant PTT by promoting greater DC, Thelper and Cytotoxic T-cell responses while lowering immunosuppressive Treg cells. These results are intriguing and studies that combine effective Th1 promoting adjuvants, lower intra-tumoral temperatures, and checkpoint inhibitors to promote these effects even more are underway.

\section{EXPERIMENTAL SECTION}

Expression protocol of endotoxin free ClearColi $Q \beta$. Expression and purification of $Q \beta$ was done as reported elsewhere 75 and slightly modified as described below. The plasmid used was a kind gift from Dr. M.G. Finn from the Georgia Institute of Technology. Competent endotoxin free ClearColiBL21 DE3 E. coli single colonies were mixed with 100 $\mathrm{mL}$ of SOB media supplemented with kanamycin (50 $\mu \mathrm{g} \cdot \mathrm{mL}-$ 1) and incubated overnight at $37{ }^{\circ} \mathrm{C}$. Grown cells were then amplified to $2 \mathrm{~L}$ of media, OD600 was monitored for $4 \mathrm{~h}$ and bacteria induced using $1 \mathrm{mM}$ of isopropyl $\beta$-D-1-thiogalactopyranoside (IPTG) when the optical density had reached ranged a value of 0.9 . Induced bacteria were incubated for $12 \mathrm{~h}$ at $37^{\circ} \mathrm{C}$. Cells were then harvested by centrifugation $(19,510 \times \mathrm{g})$ at $4{ }^{\circ} \mathrm{C}$ for $30 \mathrm{~min}$, then lysed using a cell homogenizer. Lysate was centrifuged for $1 \mathrm{~h}$ at $4{ }^{\circ} \mathrm{C}$ $(19,510 \times \mathrm{g})$, supernatant collected, and protein salted-out by mixing with $2 \mathrm{~m}$ ammonium sulfate at $4{ }^{\circ} \mathrm{C}$ for $12 \mathrm{~h}$. Protein was then collected under centrifugation $(19,510 \times \mathrm{g})$ for $30 \mathrm{~min}$ at $4{ }^{\circ} \mathrm{C}$, re-suspended in 0.1 potassium phosphate buffer $\mathrm{pH}$ 7.0. Excess lipids and membrane proteins were extracted by mixing with equal volumes of $n$-butanol and chloroform. The resulting aqueous layer was purified under sucrose gradients (10-40\%) for $12 \mathrm{~h}(87,808 \times \mathrm{g})$. Purified $\mathrm{Q} \beta$ was pelleted upon centrifugation for $4 \mathrm{~h}(179,200 \times \mathrm{g})$ and characterized by TEM, agarose gel and dynamic light scattering (Figure S2).

Electroporation of ClearColi $\mathbf{Q} \boldsymbol{\beta}$. ClearColi cells were transformed with a pET28 plasmid carrying the coat protein sequence of $Q \beta$. Electrocompetent cells were thawed on ice for $10 \mathrm{~min}$ and mixed by gentle pipetting. Then, $25 \mu \mathrm{l}$ of thawed competent reaction cells were transferred into a as chilled in a $1 \mathrm{~mL}$ microcentrifuge tube. Further, $1 \mu \mathrm{l}$ of the $\mathrm{Q} \beta$ plasmid was added to the cell suspension. The resulting mixture was chilled within an electroporation cuvette for 5 min. Electroporation was done at $25 \mu \mathrm{F}, 100 \Omega$, and $2.1 \mathrm{kV}$ for approximately 2.6 milliseconds. The electroporated cells were immediately mixed with $475 \mu \mathrm{l}$ of prewarmed $\left(37^{\circ} \mathrm{C}\right)$ SOB media inside the electroporation cuvette. The mixture was gently swirled twice, and then transfer to a sterile culture tube $(3 \mathrm{~mL})$. Bacteria was shaken under $250 \mathrm{rpm}$ at $37^{\circ} \mathrm{C}$ for $60 \mathrm{~min}$. Finally, bacteria were platted into LB media plates supplemented with kanamycin for $12 \mathrm{~h}$.

Synthesis of Croconium dye. Croconium NIR dye was synthesized according to a previously described method.2 The synthetic route of is shown in Figure 1A. Briefly $4.30 \mathrm{~g}(30.0$ $\mathrm{mmol})$ of methyl isonipecotate and $2.32 \mathrm{~g}(20.0 \mathrm{mmol})$ thiophene-2-thiol were mixed at $20 \mathrm{~mL}$ of toluene and refluxed for $2 \mathrm{~h}$. After cooling down to room temperature, the reaction mixture was filtered through a silica gel and washed with ethyl acetate. The resulting compound methyl 1-(thiophen-2-yl) piperidine-4-carboxylate (compound a) was obtained as a pale-yellow solid with $64 \%$ yield. 1H NMR (600 $\mathrm{MHz}$, Acetone) $\delta 6.75(\mathrm{dd}, \mathrm{J}=5.5,3.7 \mathrm{~Hz}, 1 \mathrm{H}), 6.65(\mathrm{dd}, \mathrm{J}=$ 5.5, $1.3 \mathrm{~Hz}, 1 \mathrm{H}), 6.16$ (dd, J = 3.7, $1.3 \mathrm{~Hz}, 1 \mathrm{H}), 3.54-3.47$ (m, $3 \mathrm{H}), 2.89-2.79(\mathrm{~m}, 2 \mathrm{H}), 2.50(\mathrm{tt}, \mathrm{J}=11.2,3.9 \mathrm{~Hz}, 1 \mathrm{H}), 2.07$ $(\mathrm{t}, \mathrm{J}=2.2 \mathrm{~Hz}, 2 \mathrm{H}), 2.03-1.96(\mathrm{~m}, 2 \mathrm{H}), 1.81(\mathrm{dtd}, \mathrm{J}=13.3$, 11.3, $4.0 \mathrm{~Hz}, 2 \mathrm{H}$ ) Figure S3. 13C NMR (151 MHz, Acetone) $\delta$ $175.24,160.34,126.89,112.71,106.22,52.06,51.82,40.91$, 28.45 (Figure S4). Next, $0.45 \mathrm{~g}$ ( $2.0 \mathrm{mmol}$ ) of compound (a) was dissolved in $10 \mathrm{~mL}$ of $0.5 \mathrm{~m}$ sodium hydroxide solution and was refluxed for $1 \mathrm{~h}$. The $\mathrm{pH}$ of the reaction mixture was acidified with $10 \%$ acetic acid to obtain [1-(thiophen-2-yl) piperidine-4-carboxylic acid] (compound b) a white precipitated form with $74 \%$ yield. $1 \mathrm{H}$ NMR (600 MHz, MeOD) $\delta$ $6.75(\mathrm{dd}, \mathrm{J}=5.4,3.7 \mathrm{~Hz}, 1 \mathrm{H}), 6.66(\mathrm{dd}, \mathrm{J}=5.5,1.3 \mathrm{~Hz}, 1 \mathrm{H})$, $6.20(\mathrm{dd}, \mathrm{J}=3.7,1.3 \mathrm{~Hz}, 1 \mathrm{H}), 3.51(\mathrm{dt}, \mathrm{J}=12.9,4.1 \mathrm{~Hz}, 2 \mathrm{H})$, $2.83(\mathrm{td}, \mathrm{J}=11.8,2.9 \mathrm{~Hz}, 2 \mathrm{H}), 2.44(\mathrm{tt}, \mathrm{J}=11.2,3.8 \mathrm{~Hz}, 1 \mathrm{H})$, 2.02 (dddd, $\mathrm{J}=13.2,5.8,3.7,1.9 \mathrm{~Hz}, 2 \mathrm{H}), 1.85$ (dtd, $\mathrm{J}=13.4$, $11.4,4.1 \mathrm{~Hz}, 2 \mathrm{H})$ Figure S5. 13C NMR (151 MHz, MeOD) $\delta$ 178.76, 160.80,126.67, 107.56, 53.12,44.59, 41.77, 30.66, 29.03 (Figure S6).

Subsequently, $0.142 \mathrm{~g}(1.00 \mathrm{mmol})$ of croconic acid was mixed with $0.422 \mathrm{~g}(2.00 \mathrm{mmol})$ of compound $\mathrm{b}$ and dissolved in the mixture of n-butanol and toluene $(30 \mathrm{~mL}, 1: 1)$, the reaction was stirred for $1 \mathrm{~h}$ under reflux. After cooling down to room temperature, the mixture was filtered and washed with methanol and the product was dried under vacuum to obtain pure croconium dye as a black solid (yield 67\%). ${ }^{1} \mathrm{H}$ NMR (600 MHz, DMSO) $\delta 12.40(\mathrm{~s}, 2 \mathrm{H}), 8.50(\mathrm{~s}$, $2 \mathrm{H}), 7.05(\mathrm{~d}, \mathrm{~J}=5.0 \mathrm{~Hz}, 2 \mathrm{H}), 4.00(\mathrm{dt}, \mathrm{J}=13.6,4.3 \mathrm{~Hz}, 4 \mathrm{H})$, $3.53(\mathrm{t}, \mathrm{J}=11.6 \mathrm{~Hz}, 4 \mathrm{H}), 2.67(\mathrm{tt}, \mathrm{J}=10.7,4.0 \mathrm{~Hz}, 2 \mathrm{H}), 2.08-$ $2.02(\mathrm{~m}, 4 \mathrm{H}), 1.79-1.65(\mathrm{~m}, 4 \mathrm{H})$ Figure S7. ${ }^{13} \mathrm{C}$ NMR (151 $\mathrm{MHz}, \mathrm{DMSO}) \delta 184.69,181.54,174.99,122.54,114.59$, 50.66, 42.52, 30.69, 27.47, 24.65 (Figure S8). ESI) $m / z$ : [M $+\mathrm{Na}]^{+}$calculated for $\mathrm{C}_{25} \mathrm{H}_{24} \mathrm{~N}_{2} \mathrm{O}_{7} \mathrm{~S}_{2}, 551.57$; found, 551.10 .

EDC/NHS coupling reaction on Croconium dye. Croconium dye $(150.0 \mathrm{mg}, 0.2800 \mathrm{mmol}), \mathrm{N}$-hydroxysuccinimide (0.097 g, $0.85 \mathrm{mmol})$, and EDC (0.13 g, $0.85 \mathrm{mmol})$ in DMF $6 \mathrm{~mL}$ were stirred at room temperature $24 \mathrm{~h}$. The DMF was removed under reduced pressure followed by dissolving the remaining residue in $20 \mathrm{ml}$ of EtOAc. The organic layer was washed with water $(3 \times 20 \mathrm{~mL})$, dried with $\mathrm{MgSO}_{4}$ and concentrated under reduced pressure. (yield $54 \%$ ). ${ }^{1} \mathrm{H}$ NMR (600 MHz, DMSO) $\delta 8.53(\mathrm{~s}, 2 \mathrm{H}), 7.08(\mathrm{~s}, 2 \mathrm{H}), 4.06(\mathrm{~d}$, $J=13.6 \mathrm{~Hz}, 4 \mathrm{H}), 3.63(\mathrm{t}, J=12.3 \mathrm{~Hz}, 4 \mathrm{H}), 2.79-2.72(\mathrm{~m}, 8 \mathrm{H})$, $2.59(\mathrm{~d}, J=16.6 \mathrm{~Hz}, 2 \mathrm{H}), 2.20(\mathrm{~d}, J=13.1 \mathrm{~Hz}, 4 \mathrm{H}), 1.90(\mathrm{~d}, J=$ $11.8 \mathrm{~Hz}, 4 \mathrm{H}$ ) Figure S9. ${ }^{33} \mathrm{C}$ NMR (151 MHz, DMSO) $\delta 175.46$, 173.23, 170.64, 170.13, 162.78, 73.73,51.16, 50.53, 36.99, $36.25,34.03,31.61,31.24,29.47,27.96,25.70,22.47,21.37$. 
Bioconjugation. A solution of $Q \beta$ VLPs $\left(1 \mathrm{mg}^{-1} \mathrm{~mL}^{-1}\right.$ in $0.1 \mathrm{~m}$ phosphate buffer, $\mathrm{pH}$ 7) was treated with a pre-mixed DMSO solution (10\%) of Croc-NHS (final concentration 0.05 $\mathrm{mm}$ ) in the mole ratio of $1: 4 \mathrm{Q} \beta$ to dye. The solution was incubated for $12 \mathrm{~h}$ at room temperature and the nonconjugated dye from the sample was removed by $10 \mathrm{kDa}$ cut off centrifugal column and then running the collected fraction through a Sephadex 25G column. Protein concentration was determined by Bradford Assay. Bioconjugation efficiency was determined based on absorption spectroscopy using Lambert-Beer law: Absorbance $(\mathrm{A})=$ extinction coefficient $(\varepsilon) \times$ molar concentration (c) $\times$ path length (l). A UV-vis spectrum of the conjugate solution was obtained (one should remember to dilute the solution to an absorbance of $<1.0$ for an accurate measurement). $A_{\max }$ was measured at the maximum wavelength $\left(\lambda_{\max }=783 \mathrm{~nm}\right)$ of croconium dye with extinction coefficient of $2.0 \times 10^{5} \mathrm{~mol}^{-1} \mathrm{~cm}^{-1} 57$ to obtain a concertation of bounded dye by $: c=A_{\max } / \varepsilon \times 1$. Q $\beta$ concentration was obtained by Bradford Assay and mol ratio of dye to $Q \beta$ in PhotoPhage was calculated and a total of 212 dyes were attached at approximately 720 potential conjugation sites.

Animal model and cell preparation for tumor Injection. The female BALB/c mice (6 weeks, 18-23 g) were purchased from Charles River laboratories. Study protocol (\#18-17) was approved by the Institutional Animal Care and Use Committee of The University of Texas at Dallas. 4T1 tumor models were established by subcutaneous injection of $1 \times 10^{6} 4 \mathrm{~T} 1$ cells on mammary fat pad of BALB/c mice as prepared: 4T1 breast cancer cells cultured in RPMI 1640 medium supplemented with 10\% Fetal Bovine Serum and $1 \%$ penicillin-streptomycin were trypsinized and washed $3 \times$ with $1 \times$ PBS. $50 \mu \mathrm{L}$ of $\sim 1.0 \times 10^{6}$ cells suspended in 1:1 mixture of PBS and Matrigel (High concentration phenol red free purchased from Corning).

Single cell suspension. On day 3 post treatment, the spleens and lymph nodes were collected from each mouse and brought into a single cell suspension. Briefly, the spleens and lymph nodes were shredded with tweezers and passed through a cell strainer using RPMI 1640 medium supplemented with $10 \%$ FBEssence, $1 \%$ penicillin-streptomycin, and $50 \mu \mathrm{M} \beta$-mercaptoethanol. The cells were centrifuged at 1,000 $\times g$ for 5 mins. The red blood cells were then lysed with $1 \times$ Red Blood Cell (RBC) Lysis Buffer for 5 mins at RT. The cells were centrifuged at $1,000 \times \mathrm{g}$ for 5 mins. The splenocytes were washed $3 \times$ with clean media. $\sim 1.0 \times$ $10^{6}$ cells were stained with anti-CD3-Pacific blue, anti-CD4PE/Cy7, anti-CD8a-FITC, anti-CD44-APC, and anti-CD62LBV605 and analyzed by flow cytometry based on gating strategy on Figure S15.

Quantification of Lung Metastatic Nodules. Tumor-bearing mice were euthanized according to preferred institutional guidelines. Lungs were inflated with $10 \%$ India ink solution in Hanks' Balanced Salt solution (HBSS) through injection of $1 \mathrm{~mL}$ solution using 25G needle into trachea. After cutting away the connective tissue, the inflated lungs were transferred to a $50-\mathrm{mL}$ conical tube containing $5 \mathrm{~mL}$ of Fekete's solution ( $35 \mathrm{~mL}$ of $95 \% \mathrm{EtOH}, 15 \mathrm{~mL}$ of $\mathrm{dH}_{2} \mathrm{O}, 5 \mathrm{~mL}$ of formaldehyde, and $2.5 \mathrm{~mL}$ of glacial acidic acid), and incubated for $24 \mathrm{~h}$ at room temperature under a chemical fume hood. The lungs were removed, and the number of metastatic nodules were counted as white spots.

\section{AUTHOR INFORMATION}

\section{Corresponding Author}

* (Word Style "FA_Corresponding_Author_Footnote"). Give contact information for the author(s) to whom correspondence should be addressed.

\section{Present Addresses}

†If an author's address is different than the one given in the affiliation line, this information may be included here.

\section{Author Contributions}

The manuscript was written through contributions of all authors. / All authors have given approval to the final version of the manuscript. / \$These authors contributed equally. (match statement to author names with a symbol)

\section{Funding Sources}

Any funds used to support the research of the manuscript should be placed here (per journal style).

Notes

Any additional relevant notes should be placed here.

\section{ACKNOWLEDGEMENTS}

J.J.G. would like to acknowledge National Science Foundation [CAREER DMR-1654405 and DMR-2003534], the Welch Foundation [AT-1989-20190330]. We thank Professor Paul Pantano and Dr. Ali Khademian for giving us the laser and all accoutrements. We thank Prof Zhenpeng Qin and Yaning Liu for helpful discussions on photothermal conversion efficiency calculations.

\section{ABBREVIATIONS}

CCR2, CC chemokine receptor 2; CCL2, CC chemokine ligand 2; CCR5, CC chemokine receptor 5; TLC, thin layer chromatography.

\section{REFERENCES}

1. Gao, D.; Guo, X.; Zhang, X.; Chen, S.; Wang, Y.; Chen, T.; Huang, G.; Gao, Y.; Tian, Z.; Yang, Z. Multifunctional phototheranostic nanomedicine for cancer imaging and treatment. Materials Today Bio. 2020, 5, 100035. DOI: 10.1016/j.mtbio.2019.100035

2. Chen, F.; Cai, W. Nanomedicine for targeted photothermal cancer therapy: where are we now?. Nanomedicine 2015, 10 (1), 1-3. DOI: $10.2217 / \mathrm{nnm} .14 .186$

3. Pinto, A.; Pocard, M. Photodynamic therapy and photothermal therapy for the treatment of peritoneal metastasis: a systematic review. Pleura Peritoneum 2018, 3 (4), 2018012420180124. DOI: $10.1515 /$ pp-2018-0124

4. Krysko, D. V.; Agostinis, P.; Krysko, O.; Garg, A. D.; Bachert, C.; Lambrecht, B. N.; Vandenabeele, P. Emerging role of damageassociated molecular patterns derived from mitochondria in inflammation. Trends Immunol. 2011, 32 (4), 157-64. DOI: 10.1016/j.it.2011.01.005 
5. Chen, G. Y.; Nunez, G. Sterile inflammation: sensing and reacting to damage. Nat. Rev. Immunol. 2010, 10 (12), 826-37. DOI: $10.1038 /$ nri2873

6. Hernandez, C.; Huebener, P.; Schwabe, R. F. Damage-associated molecular patterns in cancer: a double edged sword. Oncogene 2016, 35 (46), 5931-5941. DOI: 10.1038/onc.2016.104 7. West, C. L.; Doughty, A. C. V.; Liu, K.; Chen, W. R. Monitoring tissue temperature during photothermal therapy for cancer. $J$ BioX Res 2019, 2 (4), 159-168. DOI: 10.1097/jbr.0000000000000050

8. Li, L.; Yang, S.; Song, L.; Zeng, Y.; He, T.; Wang, N.; Yu, C.; Yin, T.; Liu, L.; Wei, X.; Wu, Q.; Wei, Y.; Yang, L.; Gong, C. An Endogenous Vaccine Based on Fluorophores and Multivalent Immunoadjuvants Regulates Tumor Micro-Environment for Synergistic Photothermal and Immunotherapy. Theranostics 2018, 8 (3), 860-873. DOI : $10.7150 /$ thno.19826

9. Wang, C.; Xu, L.; Liang, C.; Xiang, J.; Peng, R.; Liu, Z. Immunological responses triggered by photothermal therapy with carbon nanotubes in combination with anti-CTLA-4 therapy to inhibit cancer metastasis. Adv. Mater. 2014, 26 (48), 8154-62. DOI : 10.1002/adma.201402996

10. Wangzhong, S.; Sha, H.; William, J. S.; Adah, A. Review of the progress toward achieving heat confinement-the holy grail of photothermal therapy. J. Biomed. Opt. 2017, 22 (8), 1-16. DOI: 10.1117/1.JBO.22.8.080901

11. Yang, Z.; Sun, Z.; Ren, Y.; Chen, X.; Zhang, W.; Zhu, X.; Mao, Z.; Shen, J.; Nie, S. Advances in nanomaterials for use in photothermal and photodynamic therapeutics. Mol. Med. Rep. 2019, 20 (1), 5-15. DOI: 10.3892/mmr.2019.10218

12. Jaque, D.; Martinez Maestro, L.; del Rosal, B.; Haro-Gonzalez, P.; Benayas, A.; Plaza, J. L.; Martin Rodriguez, E.; Garcia Sole, J. Nanoparticles for photothermal therapies. Nanoscale 2014, 6 (16), 9494-9530. DOI : 10.1039/C4NR00708E

13. Lee, S.; George Thomas, R.; Ju Moon, M.; Ju Park, H.; Park, I.K.; Lee, B. I.; Yeon Jeong, Y. Near-Infrared Heptamethine Cyanine Based Iron Oxide Nanoparticles for Tumor Targeted Multimodal Imaging and Photothermal Therapy. Scientific Reports 2017, 7 (1), 2108. DOI: 10.1038/s41598-017-01108-5.

14. Wu, F.; Lu, Y.; Mu, X.; Chen, Z.; Liu, S.; Zhou, X.; Liu, S.; Li, Z., Intriguing $\mathrm{H}$-Aggregates of Heptamethine Cyanine for ImagingGuided Photothermal Cancer Therapy. ACS Appl. Mater. Interfaces 2020, 12 (29), 32388-32396. DOI: 10.1021/acsami.0c07608

15. Li, X.; Peng, X.-H.; Zheng, B.-D.; Tang, J.; Zhao, Y.; Zheng, B.Y.; Ke, M.-R.; Huang, J.-D., New application of phthalocyanine molecules: from photodynamic therapy to photothermal therapy by means of structural regulation rather than formation of aggregates. Chem. Sci. 2018, 9 (8), 2098-2104. DOI: 10.1039/C7SC05115H

16. Zheng, B.-D.; He, Q.-X.; Li, X.; Yoon, J.; Huang, J.-D., Phthalocyanines as contrast agents for photothermal therapy. Coord. Chem. Rev. 2021, 426, 213548. DOI: 10.1016/j.ccr.2020.213548

17. Cheung, C. C. L.; Ma, G.; Karatasos, K.; Seitsonen, J.; Ruokolainen, J.; Koffi, C.-R.; Hassan, H. A. F. M.;

Al-Jamal, W. T., Liposome-Templated Indocyanine Green J- Aggregates for In Vivo Near-Infrared Imaging and Stable Photothermal Heating. Nanotheranostics 2020, 4 (2), 91-106. DOI: $10.7150 /$ ntno.41737

18. Holzer, W.; Mauerer, M.; Penzkofer, A.; Szeimies, R. M.; Abels, C.; Landthaler, M.; Baumler, W., Photostability and thermal stability of indocyanine green. J. Photochem. Photobiol. B, Biol. 1998, 47 (2), 155-164. DOI: 10.1016/S10111344(98)00216-4
19. Vines, J. B.; Yoon, J.-H.; Ryu, N.-E.; Lim, D.-J.; Park, H., Gold Nanoparticles for Photothermal Cancer Therapy. Front. Chem. 2019, 7, 167-167. DOI: 10.3389/fchem.2019.00167

20. Sobhani, Z.; Behnam, M. A.; Emami, F.; Dehghanian, A.; Jamhiri, I., Photothermal therapy of melanoma tumor using multiwalled carbon nanotubes. Int. J. Nanomedicine 2017, 12, 45094517. DOI: $10.2147 /$ IJN.S134661

21. Estelrich, J.; Busquets, M. A., Iron Oxide Nanoparticles in Photothermal Therapy. Molecules 2018, 23 (7), 1567. DOI: 10.3390/molecules23071567

22. Zhou, B.; Li, Y.; Niu, G.; Lan, M.; Jia, Q.; Liang, Q., Near-Infrared Organic Dye-Based Nanoagent for the

Photothermal Therapy of Cancer. ACS Appl. Mater. Interfaces 2016, 8 (44), 29899-29905. DOI: 10.1021/acsami.6b07838

23. Avirah, R. R.; Jyothish, K.; Ramaiah, D., Infrared Absorbing Croconaine Dyes: Synthesis and Metal Ion Binding Properties. J. Org. Chem. 2008, 73 (1), 274-279. DOI: 10.1021/jo702209a 24. Tang, L.; Zhang, F.; Yu, F.; Sun, W.; Song, M.; Chen, X.; Zhang, X.; Sun, X. Croconaine nanoparticles with enhanced tumor accumulation for multimodality cancer theranostics. Biomaterials 2017, 129, 28-36. DOI: 10.1016/j.biomaterials.2017.03.009 25. Harmatys, K. M.; Battles, P. M.; Peck, E. M.; Spence, G. T.; Roland, F. M.; Smith, B. D., Selective photothermal inactivation of cells labeled with near-infrared croconaine dye. Chem. Commun. 2017, 53 (71), 9906-9909. Doi: 10.1039/C7CC05196D

26. Spence, G. T.; Hartland, G. V.; Smith, B. D. Activated photothermal heating using croconaine dyes. Chem. Sci. 2013, 4 (11), 4240-4244. DOI: 10.1039/C3SC51978C

27. Benjamin, C.; Brohlin, O.; Shahrivarkevishahi, A.; Gassensmith, J. J., Chapter 11 - Virus like particles: fundamental concepts, biological interactions, and clinical applications. In Nanoparticles for Biomedical Applications, Chung, E. J.; Leon, L.; Rinaldi, C., Eds. Elsevier: 2020, 153-174. DOI: 10.1016/B9780-12-816662-8.00011-4

28. Herbert, F. C.; Brohlin, O. R.; Galbraith, T.; Benjamin, C.; Reyes, C. A.; Luzuriaga, M. A.; Shahrivarkevishahi, A.; Gassensmith, J. J., Supramolecular Encapsulation of Small-Ultrared Fluorescent Proteins in Virus-Like Nanoparticles for Noninvasive In Vivo Imaging Agents. Bioconjugate Chem. 2020, 31 (5), 1529-1536. DOI: 10.1021/acs.bioconjchem.0c00190

29. Wang, Q.; Lin, T.; Tang, L.; Johnson, J. E.; Finn, M. G. Icosahedral Virus Particles as Addressable Nanoscale Building Blocks. Angew. Chem. Int. 2002, 41 (3), 459-462. DOI: 10.1002/15213773(20020201)41:3<459::aid-anie459>3.0.co;2-o

30. Chung, Y. H.; Cai, H.; Steinmetz, N. F., Viral nanoparticles for drug delivery, imaging, immunotherapy, and theranostic applications. Adv. Drug Deliv. Rev. 2020,156, 214-235. DOI: 10.1016/j.addr.2020.06.024

31. Park, J.; Chariou, P. L.; Steinmetz, N. F., Site-Specific Antibody Conjugation Strategy to Functionalize Virus-Based Nanoparticles. Bioconjugate Chem. 2020, 31 (5), 1408-1416. DOI : 10.1021/acs.bioconjchem.0c00118

32. Aanei, I. L.; Francis, M. B. Dual Surface Modification of Genome-Free MS2 Capsids for Delivery Applications. Methods Mol Biol. 2018, 1776, 629-642. DOI: 10.1007/978-1-4939-78083_40

33. Purwar, M.; Pokorski, J. K.; Singh, P.; Bhattacharyya, S.; Arendt, H.; DeStefano, J.; La Branche, C. C.; Montefiori, D. C.; Finn, M. G.; Varadarajan, R. Design, display and immunogenicity of HIV1 gp120 fragment immunogens on virus-like particles. Vaccine 2018, 36 (42), 6345-6353. DOI: 10.1016/j.vaccine.2018.07.032

34. Benjamin, C. E.; Chen, Z.; Kang, P.; Wilson, B. A.; Li, N.; Nielsen, S. O.; Qin, Z.; Gassensmith, J. J. Site- Selective Nucleation and Size Control of Gold Nanoparticle Photothermal Antennae on 
the Pore Structures of a Virus. J Am Chem Soc. 2018, 140 (49), 17226-17233. DOI: $10.1021 /$ jacs.8b10446

35. Fiedler, J. D.; Fishman, M. R.; Brown, S. D.; Lau, J.; Finn, M. G. Multifunctional Enzyme Packaging and Catalysis in the Q $\beta$ Protein Nanoparticle. Biomacromolecules 2018, 19 (10), 39453957. DOI: 10.1021 /acs.biomac.8b00885

36. Rampoldi, A.; Crooke, S. N.; Preininger, M. K.; Jha, R.; Maxwell, J.; Ding, L.; Spearman, P.; Finn, M. G.; Xu, C. Targeted Elimination of Tumorigenic Human Pluripotent Stem Cells Using Suicide-Inducing Virus-like Particles. ACS chemical biology 2018, 13 (8), 2329-2338. DOI: 10.1021/acschembio.8b00490

37. Yin, Z.; Wu, X.; Kaczanowska, K.; Sungsuwan, S.; Comellas Aragones, M.; Pett, C.; Yu, J.; Baniel, C.; Westerlind, U.; Finn, M. G.; Huang, X. Antitumor Humoral and T Cell Responses by Mucin-1 Conjugates of Bacteriophage $\mathrm{Q} \beta$ in Wild-type Mice. ACS chemical biology 2018, 13 (6), 1668-1676. DOI: 10.1021/acschembio.8b00313

38. Shoeb, E.; Hefferon, K. Future of cancer immunotherapy using plant virus-based nanoparticles. Future Sci OA. 2019, 5 (7), FS0401-FSO401. DOI: 10.2144/fsoa-2019-0001

39. Wang, C.; Fiering, S. N.; Steinmetz, N. F. Cowpea Mosaic Virus Promotes Anti-Tumor Activity and Immune Memory in a Mouse Ovarian Tumor Model. Advanced Therapeutics 2019, 2 (5), 1900003. DOI: 10.1021/acsnano.9607865

40. Pitek, A. S.; Hu, H.; Shukla, S.; Steinmetz, N. F. Cancer Theranostic Applications of Albumin-Coated Tobacco Mosaic Virus Nanoparticles. Appl. Mater. Interfaces. 2018, 10 (46), 39468-39477. DOI: 10.1021/acsami.8b12499

41. Finbloom, J. A.; Han, K.; Aanei, I. L.; Hartman, E. C.; Finley, D. T.; Dedeo, M. T.; Fishman, M.; Downing, K. H.; Francis, M. B. Stable Disk Assemblies of a Tobacco Mosaic Virus Mutant as Nanoscale Scaffolds for Applications in Drug Delivery. Bioconjugate Chemistry 2016, 27 (10), 2480-2485. DOI: 10. 1021/acs.bioconjchem.6b00424

42. Mohsen, M. O.; Speiser, D. E.; Knuth, A.; Bachmann, M. F. Virus-like particles for vaccination against cancer. WIRES Nanomed Nanob. 2020, 12 (1), e1579. DOI: 10.1002/wnan.1579

43. Klimek, L.; Kundig, T.; Kramer, M. F.; Guethoff, S.; JensenJarolim, E.; Schmidt-Weber, C. B.; Palomares, O.; Mohsen, M. O.; Jakob, T.; Bachmann, M. Virus-like particles (VLP) in prophylaxis and immunotherapy of allergic diseases. Allergo J Int. 2018, 27 (8), 245-255. DOI: 10.007/s40629-018-0074-y

44. Welch, R. P.; Lee, H.; Luzuriaga, M. A.; Brohlin, O. R.; Gassensmith, J. J. Protein-Polymer Delivery: Chemistry from the Cold Chain to the Clinic. Bioconjugate Chem. 2018, 29 (9), 2867-2883. DOI: 10.1021/acs.bioconjchem.8b00483

45. Lee, H.; Shahrivarkevishahi, A.; Lumata, J. L.; Luzuriaga, M. A.; Hagge, L. M.; Benjamin, C. E.; Brohlin, O. R.; Parish, C. R.; Firouzi, H. R.; Nielsen, S. O.; Lumata, L. L.; Gassensmith, J. J. Supramolecular and biomacromolecular enhancement of metal-free magnetic resonance imaging contrast agents. Chem. Sci. 2020, 11 (8), 2045-2050. DOI: 10.1039/C9SC05510J

46. Dharmarwardana, M.; Martins, A. F.; Chen, Z.; Palacios, P. M.; Nowak, C. M.; Welch, R. P.; Li, S.; Luzuriaga, M. A.; Bleris, L.; Pierce, B. S.; Sherry, A. D.; Gassensmith, J. J. Nitroxyl Modified Tobacco Mosaic Virus as a Metal-Free High-Relaxivity MRI and EPR Active Superoxide Sensor. Mol. Pharmaceutics 2018, 15 (8), 2973-2983. DOI: 10.1021/acs.molpharmaceut.8b00262

47. Rohovie, M. J.; Nagasawa, M.; Swartz, J. R. Virus-like particles: Next-generation nanoparticles for targeted therapeutic delivery. Bioeng. Transl. Med. 2017, 2 (1), 43-57. DOI: 10.1002/btm2.10049

48. $\quad$ Chen, Z.; Boyd, S. D.; Calvo, J. S.; Murray, K. W.; Mejia, G. L.; Benjamin, C. E.; Welch, R. P.; Winkler, D. D.; Meloni, G.;
D'Arcy, S.; Gassensmith, J. J. Fluorescent Functionalization across Quaternary Structure in a Virus-like Particle. Bioconjugate Chem. 2017, 28 (9), 2277-2283. DOI: 10.1021/acs.bioconjchem.7b00305

49. Chen, Z.; Detvo, S. T.; Pham, E.; Gassensmith, J. J. Making Conjugation-induced Fluorescent PEGylated Virus-like Particles by Dibromomaleimide-disulfide Chemistry. J. Visualized Exp. 2018, 135, e57712. DOI: 10.3791/57712

50. $\quad$ Chen, Z.; Li, N.; Chen, L.; Lee, J.; Gassensmith, J. J. Dual Functionalized Bacteriophage $\mathrm{Q} \beta$ as a Photocaged Drug Carrier. Small 2016, 12 (33), 4563-4571. DOI: 10.1002/smll.201601053

51. Chen, Z.; Li, N.; Li, S.; Dharmarwardana, M.; Schlimme, A.; Gassensmith, J. J. Viral chemistry: the chemical functionalization of viral architectures to create new technology. Wiley Interdiscip. Rev.: Nanomed. Nanobiotechnol. 2016, 8 (4), 512-534. DOI: 10.1002/wnan.1379

52. Bear, A. S.; Kennedy, L. C.; Young, J. K.; Perna, S. K.; Mattos Almeida, J. P.; Lin, A. Y.; Eckels, P. C.; Drezek, R. A.; Foster, A. E., Elimination of metastatic melanoma using gold nanoshell-enabled photothermal therapy and adoptive T cell transfer. PloS one. 2013, 8 (7), e69073. DOI: 10.1371/journal.pone.0069073. 53. Mohsen, M. O.; Gomes, A. C.; Vogel, M.; Bachmann, M. F. Interaction of Viral Capsid-Derived Virus-Like Particles (VLPs) with the Innate Immune System. Vaccines 2018, 6 (3), 37. DOI: $10.3390 /$ vaccines6030037

54. Zepeda-Cervantes, J.; Ramirez-Jarquin, J. O.; Vaca, L. Interaction Between Virus-Like Particles (VLPs) and Pattern Recognition Receptors (PRRs) From Dendritic Cells (DCs): Toward Better Engineering of VLPs. Front. Immunol. 2020, 11, 1100. DOI: $10.3389 /$ fimmu.2020.01100.

55. Qian, C.; Liu, X.; Xu, Q.; Wang, Z.; Chen, J.; Li, T.; Zheng, Q.; Yu, H.; Gu, Y.; Li, S.; et al. Recent Progress on the Versatility of VirusLike Particles. Vaccines 2020, 8 (1). DOI:10.3390/vaccines8010139

56. Song, X.; Foley, J. W. A new water-soluble near-infrared croconium dye. Dyes and Pigments 2008, 78 (1), 60-64. DOI: 10.1016/j.dyepig.2007.10.006

57. Liu, Y.; Ai, K.; Liu, J.; Deng, M.; He, Y.; Lu, L., Dopamine-Melanin Colloidal Nanospheres: An Efficient Near-Infrared Photothermal Therapeutic Agent for In Vivo Cancer Therapy. Adv. Mater. 2013, 25 (9), 1353-1359. DOI: 10.1002/adma.201204683

58. Kang, P.; Chen, Z.; Nielsen, S. O.; Hoyt, K.; D'Arcy, S.; Gassensmith, J. J.; Qin, Z. Molecular Hyperthermia: Spatiotemporal Protein Unfolding and Inactivation by Nanosecond Plasmonic Heating. Small 2017, 13 (36). DOI: 10.1002/smll.201700841 59. Marabelle, A.; Andtbacka, R.; Harrington, K.; Melero, I.; Leidner, R.; de Baere, T.; Robert, C.; Ascierto, P. A.; Baurain, J. F.; Imperiale, M.; Rahimian, S.; Tersago, D.; Klumper, E.; Hendriks, M.; Kumar, R.; Stern, M.; Ohrling, K.; Massacesi, C.; Tchakov, I.; Tse, A.; Douillard, J. Y.; Tabernero, J.; Haanen, J.; Brody, J. Starting the fight in the tumor: expert recommendations for the development of human intratumoral immunotherapy (HIT-IT). Ann Oncol 2018, 29 (11), 2163-2174. DOI: 10.1093/annonc/mdy 423

60. Steinman, R. M., Linking innate to adaptive immunity through dendritic cells. Novartis Found. Symp. 2006, 279, 1019; discussion 109-13, 216-9. DOI: 10.1002/9780470035399

61. Wculek, S. K.; Cueto, F. J.; Mujal, A. M.; Melero, I.; Krummel, M. F.; Sancho, D., Dendritic cells in cancer immunology and immunotherapy. Nat. Rev. Immunol. 2020, 20 (1), 7-24. DOI: 10.1038/s41577-019-0210-z

62. Wang, J.; Chang, Y.; Luo, H.; Jiang, W.; Xu, L.; Chen, T.; Zhu, X., Designing immunogenic nanotherapeutics for photothermal- 
triggered immunotherapy involving reprogramming immunosuppression and activating systemic anti-tumor responses. Biomaterials 2020, 255, 120153. DOI: 10.1016/j.biomaterials.2020.120153

63. Guo, Y.; Ran, Y.; Wang, Z.; Cheng, J.; Cao, Y.; Yang, C.; Liu, F.; Ran, H., Magnetic-responsive and targeted cancer nanotheranostics by PA/MR bimodal imaging-guided photothermally triggered immunotherapy. Biomaterials 2019, 219, 119370. DOI: 10.1016/j.biomaterials.2019.119370

64. Mellman, I.; Coukos, G.; Dranoff, G., Cancer immunotherapy comes of age. Nature 2011, 480 (7378), 480- 489. DOI: $10.1038 /$ nature10673

65. Janeway, C. A., Jr.; Bottomly, K., Signals and signs for lymphocyte responses. Cell 1994, 76 (2), 275-85. DOI: 10.1016/0092-8674(94)90335-2

66. Mohsen, M. O.; Gomes, A. C.; Vogel, M.; Bachmann, M. F., Interaction of Viral Capsid-Derived Virus-Like Particles (VLPs) with the Innate Immune System. Vaccines 2018, 6 (3), 37. DOI: 10.3390/vaccines6030037

67. Grgacic, E. V. L.; Anderson, D. A. Virus-like particles: passport to immune recognition. Methods 2006, 40 (1), 60-65. DOI: 10.1016/j.ymeth.2006.07.018

68. Kaczmarek, A.; Vandenabeele, P.; Krysko, Dmitri V. Necroptosis: The Release of Damage-Associated Molecular Patterns and Its Physiological Relevance. Immunity 2013, 38 (2), 209223. DOI: 10.1016/j.immuni.2013.02.003

69. Xu, P.; Liang, F. Nanomaterial-Based Tumor Photothermal Immunotherapy. Int J Nanomedicine. 2020, 15, 9159-9180. DOI: $10.2147 /$ IJN.S249252

70. Cheng, H.-W.; Tsao, H.-Y.; Chiang, C.-S.; Chen, S.-Y. Advances in Magnetic Nanoparticle-Mediated Cancer ImmuneTheranostics. Adv Healthc Mater .2021, 10 (1), 2001451. DOI: 10.1002/adhm.202001451

71. M. J. O’Melia, N. A. Rohner, M.P. Manspeaker, D. M. Francis, H. T. Kissick, S. N. Thomas. Quality of CD8+ T cell immunity evoked in lymph nodes is compartmentalized by route of antigen transport and functional in tumor context. Sci. Adv. 2020, 6 (50), eabd7134. DOI: 10.1126/sciadv.abd7134

72. Z. S. Buchwald, T. H. Nasti, J. Lee, C. S. Eberhardt, A. Wieland, S. J. Im, D. Lawson, W. Curran, R. Ahmed, M. K. Khan. Tumor-draining lymph node is important for a robust abscopal effect stimulated by radiotherapy. JITC. 2020, 8 (2) , e000867. DOI :10.1136/jitc-2020-000867

73. Li, C.; Jiang, P.; Wei, S.; Xu, X.; Wang, J. Regulatory T cells in tumor microenvironment: new mechanisms, potential therapeutic strategies and future prospects. Mol Cancer. 2020, 19 (1), 116. DOI: 10.1186/s12943-020-01234-1

74. Tormoen, G. W.; Crittenden, M. R.; Gough, M. J. Role of the immunosuppressive microenvironment in immunotherapy. Adv Radiat Oncol 2018, 3 (4), 520-526. DOI: 10.1016/j.adro.2018.08.018

75. P.W. Lee, S.A. Isarov, J.D. Wallat, S.K. Molugu, S. Shukla, J.E. Sun, J. Zhang, Y. Zheng, M. Lucius Dougherty, D. Konkolewicz, P. L. Stewart, N. F. Steinmetz, M. J. Hore, J. K. Pokorski. Polymer Structure and Conformation Alter the Antigenicity of Virus-like Particle-Polymer Conjugates. JACS. 2017, 139, 3312-3315. DOI: $10.1021 /$ jacs.6b11643 


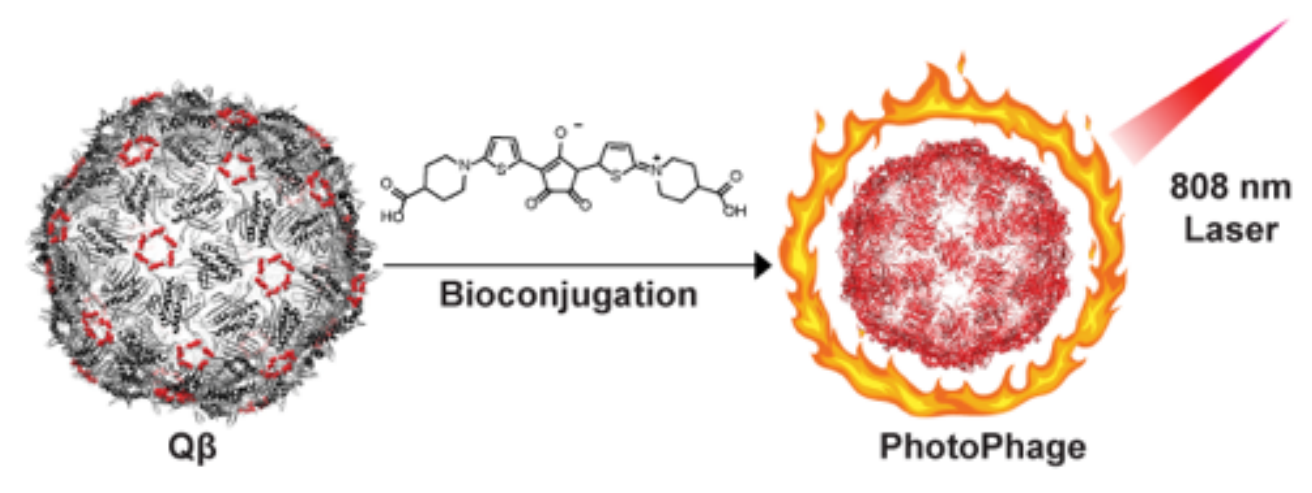

